\title{
Characterization of the Properties of a Human Homologue of Escherichia coli RecQ from Xeroderma Pigmentosum Group $C$ and from HeLa Cells
}

\author{
Shusuke Tada, Jun Yanagisawa, Tadao Sonoyama, Atsuko Miyajima*, Masayuki Seki**, Michio \\ $\mathbf{U i}^{\ddagger}$, and Takemi Enomoto ${ }^{* * \dagger}$ \\ Department of Physiological Chemistry, Faculty of Pharmaceutical Sciences, University of Tokyo, 7-3-1 \\ Hongo, Bunkyo-ku, Tokyo 113, Japan
}

Key words: DNA helicase Q1/human homologue/RecQ/xeroderma pigmentosum/complementation group C cells/HeLa cells

\begin{abstract}
$A B S T R A C T$. We showed that DNA-dependent ATPase Q1 (DNA helicase Q1) from xeroderma pigmentosum complementation group $\mathrm{C}$ (XP-C) cells elutes from FPLC Mono $Q$ column at higher concentrations of $\mathrm{KCl}$ than that from other human cells (35). We purified DNA helicase Q1 from XP-C and HeLa cells. The purified fractions of both cells contained a major polypeptide with a molecular mass of $73 \mathrm{kDa}$ and had the same enzymatic properties, including salt- and temperature-sensitivity. Characterization using an anti-DNA helicase Q1 antibody indicated that this enzyme localized in the nuclei and was not modified by incorporating phosphate groups through phosphorylation and ADP-ribosylation. No interactions of DNA helicase Q1 with other proteins were indicated by immunoprecipitation of the helicase from crude extracts. No difference was observed in XP-C cells in intracellular localization of DNA helicase Q1, phosphorylation, and the interaction with other proteins as compared to HeLa cells.
\end{abstract}

The unwinding of double-stranded DNA is crucial for the processes of DNA repair, recombination, and transcription as well as DNA replication. A class of enzymes, designated DNA helicases, accomplish this task while consuming energy produced by the hydrolysis of ATP $(11,13,14,27)$. Thus these enzymes contain an intrinsic DNA-dependent ATPase activity.

A large number of mammalian DNA helicases have been identified mainly by biochemical assay. A list of these helicases has been presented $(14,27)$. However, the roles of only a few mammalian helicases have been identified in cellular metabolism. Mutants of mammalian cells defective in DNA repair will be useful tools for the identification of enzymes and proteins involved in

\footnotetext{
* Present address: Division of Pharmacology, Biological Safety Research Center, National Institute of Health Sciences, 1-18-1 Kamiyoga, Setagaya-ku, Tokyo 158.

** Present address: Department of Molecular Cell Biology, Faculty of Pharmaceutical Sciences Tohoku University, Aoba Aramaki, Aoba-ku, Sendai, Miyagi 980-77.

$\ddagger \quad$ Present address: Ui Special Laboratory, RIKEN Institute, 2-1 Hirosawa, Wako, Saitama 351-01.

$\dagger$ To whom correspondence should be addressed: Tel, +81-22217-6874; Fax, +81-22-217-6873

Abbreviations: PBS, $\mathrm{Ca}^{2+}$ and $\mathrm{Mg}^{2+}$-free phosphate buffered saline; ERCC, excision repair cross-complementing; FITC, fluorescein isothiocyanate; FPLC, fast protein liquid chromatography; XP, xeroderma pigmentosum.
}

DNA repair and for the investigating the molecular mechanism of the process. Cells from patients with xeroderma pigmentosum (XP) are defective in the incision step of nucleotide excision repair. XP is now categorized into the seven complementation groups, A to $\mathrm{G}$, and a variant (30). ERCC (excision repair cross-complementing) 2 and $E R C C 3$ are human genes isolated on the basis of their complementing excision repair defects in rodent cell lines $(32,33)$. They are responsible for the defect of xeroderma pigmentosum complementing group D (5) and B (34) cells, respectively. The ERCC2 and 3 gene products were confirmed to have helicase activity $(19,25)$ and to be the subunits of transcription factor TFIIH $(4,19,20)$. Thus, it is apparent that the $E R C C 2$ and $E R C C 3$ helicases are involved in the processes of transcription and DNA excision repair.

We studied DNA-dependent ATPases in XP cells. Human cells contain at least five DNA-dependent ATPase activities that are separable by means of fast protein liquid chromatography (FPLC) Mono Q column chromatography. We found that the elution profile of one of the five DNA-dependent ATPases, ATPase Q1, from XP group C cells (XP-C) was altered compared with those of ATPase Q1 from human cells normal in repair and XP cells of complementation groups A to $G$ except $C$. The elution profile of DNA-dependent ATPase Q1 was also altered in five cell lines de- 
rived from five patients belonging to complementation group $\mathrm{C}$, indicating that the defect of XP-C cells in DNA repair is due to an alteration of DNA-dependent ATPase Q1 (35). We therefore purified DNA-dependent ATPase Q1 from HeLa cells (23). The microinjection of the purified ATPase Q1, however, neither restored unscheduled DNA synthesis in XP-C cells nor complemented extracts from XP-C cells for cell-free DNA repair synthesis. In addition, a protein complex consisting of 125 and $58 \mathrm{kDa}$ proteins has been purified, which complements DNA repair activity of the extracts from XP-C cells in a cell-free system, and the cDNAs for the proteins have been cloned (12). The larger subunit of the complex is an N-terminally extended version of the XP-C complementing gene product $(10,12)$. These results indicated that ATPase Q1 itself is not the corresponding protein for the defective DNA repair in XP-C cells.

In parallel with these studies, we cloned the cDNA encoding DNA-dependent ATPase Q1. The seven motifs conserved in DNA and RNA helicase superfamily are conserved in ATPase Q1 (helicase Q1). The predicted amino acid sequence of helicase Q1 has homology with the $E$. coli RecQ protein (24). This was the first case of cloning a cDNA encoding a RecQ homologue of higher eukaryotic cells. Puranam and Blackshear also cloned the same gene (18). E. coli RecQ protein has both DNAdependent ATPase and DNA helicase activity (28) and is involved in the RecF pathway of conjugational recombination (15). However, little is known about the function of RecQ in this pathway.

DNA helicase Q1 and E. coli RecQ protein exhibited striking sequence homology to the Saccharomyces cerevisiae TPS1 (also called $S G S 1$ ) gene product. A mutation of this gene reverses the slow growth phenotype of topoisomerase III mutants (6). The interaction of the TPS1 protein with DNA topoisomerase II has been confirmed using a two-hybrid system (31). However, the function played by this protein remains to be clarified. In addition, the biochemical properties of this protein have not yet been examined.

In this study, we characterized the properties of DNA helicase Q1 (human RecQ) from XP-C cells using a purified fraction and an anti-helicase $\mathrm{Q} 1$ antibody. In addition, we compared the properties with those of the Q1 from $\mathrm{HeLa}$ cells.

\section{MATERIALS AND METHODS}

Materials. Single-stranded DNA-cellulose was prepared using heat-denatured calf thymus DNA essentially according to Alberts and Herrick (1), with a slight modification, as described (26). All other chemicals and DNAs were as described $(21,22)$.

Buffers. Hypotonic buffer contained $20 \mathrm{mM}$ Hepes-KOH,
pH 7.5, $5 \mathrm{mM} \mathrm{KCl}, 1.5 \mathrm{mM} \mathrm{MgCl}$. Buffer 1 contained $20 \mathrm{mM}$ potassium phosphate buffer, $\mathrm{pH} 7.5,0.1 \mathrm{mM} \mathrm{Na}_{3}$ EDTA, 1 $\mathrm{mM}$ 2-mercaptoethanol, $0.25 \mathrm{mM}$ phenylmethylsulfonyl fluoride and $1 \%$ ethanol. Buffer 2 contained all the components of buffer $1,20 \%(\mathrm{v} / \mathrm{v})$ ethylene glycol, and $0.01 \%$ Triton X100. Buffer 3 contained all the components of buffer $1,50 \%$ (v/v) glycerol, $0.01 \%$ Triton X-100 and $100 \mathrm{mM} \mathrm{KCl}$.

ATPase Assay. The standard reaction mixture $(50 \mu \mathrm{l})$ containing $50 \mathrm{mM}$ Tris- $\mathrm{HCl}, \mathrm{pH} 7.5,20 \mathrm{mM}$ 2-mercaptoethanol, $5 \mathrm{mM} \mathrm{MgCl} 2,5 \mathrm{mM}$ ATP, $0.5 \mathrm{mg} / \mathrm{ml}$ of BSA and, $5 \mu \mathrm{g}$ of heat-denatured DNA was incubated at $37^{\circ} \mathrm{C}$ for $60 \mathrm{~min}$. The amount of ADP produced was determined as described by Korn and Yanofsky (7). One unit of activity is defined as the amount of enzyme that hydrolyzes $1 \mathrm{nmol}$ of ATP $/ \mathrm{h}$ at $37^{\circ} \mathrm{C}$.

DNA Helicase Assay. The standard reaction mixture (20 $\mu \mathrm{l})$ consisted of $50 \mathrm{mM}$ Tris- $\mathrm{HCl}, \mathrm{pH} 7.5,20 \mathrm{mM}$ 2-mercaptoethanol, $2 \mathrm{mM} \mathrm{MgCl}_{2}, 5 \mathrm{mM}$ ATP, $0.5 \mathrm{mg} / \mathrm{ml} \mathrm{BSA}$, and $0.017 \mathrm{pmol}$ of ${ }^{32} \mathrm{P}$-labeled DNA helicase substrate. The DNA helicase substrate was prepared as described (22). The reaction was terminated by chilling the reaction mixture to $0^{\circ} \mathrm{C}$ followed by adding $5 \mu \mathrm{l}$ of a solution containing $75 \mathrm{mM} \mathrm{Na}_{3}$ EDTA, 0.1\% bromophenol blue, and 30\% (v/v) glycerol. After cooling at $0^{\circ} \mathrm{C}$ for $20 \mathrm{~min}$, a $25 \mu \mathrm{l}$ aliquot was loaded on a $12 \%$ polyacrylamide gel in TBE buffer $(89 \mathrm{mM}$ Tris-borate, $\mathrm{pH}$ 8.2, and 2 mM EDTA), and then resolved by electrophoresis followed by autoradiography at $-80^{\circ} \mathrm{C}$. DNA helicase activity was determined by densitometrically scanning the autoradiograms. The activity was normalized by the following formula: $X=P /(P+S)$, where $P$ (products) is the value of the displaced oligonucleotides and S (substrates) is the value of nondisplaced substrates. The helicase activity is expressed as a percentage of the control value: $100 \times[(\mathrm{Xsample}-\mathrm{Xn} /(\mathrm{Xp}-\mathrm{Xn})]$, where $\mathrm{Xn}$ is the negative control assayed at $37^{\circ} \mathrm{C}$ without enzyme, and $\mathrm{Xp}$ is the positive control when the reaction mixture containing no enzyme was heated in boiling water for 2 $\min$.

Cell Lines and Cell Culture. The cells were simian virus 40-transformed fibroblasts, XP4PASV (XP group C) and WI38VA13 (normal human fibroblasts), and HeLa S3 cells. XP4PASV cells were provided by L. Daya-Grosjean and A. Sarasin, Institut de Recherche Scientifique (Villejuit, French). XP4PASV and WI38VA13 cells were cultured at $37^{\circ} \mathrm{C}$ in Dulbecco's modified Eagle's medium containing 7\% fetal bovine serum, $100 \mu \mathrm{g} / \mathrm{ml}$ streptomycin sulfate, and $100 \mathrm{units} / \mathrm{ml}$ penicillin $\mathrm{G}$ potassium. Suspensions of HeLa cells were maintained in RPMI 1640 containing 7\% calf serum and antibiotics.

Preparation of Nuclear Extracts. Cells $\left(7 \times 10^{8}\right)$ were washed twice with ice-cold $\mathrm{Ca}^{2+}$ and $\mathrm{Mg}^{2+}$-free phosphatebuffered saline (PBS) and suspended in hypotonic buffer. After swelling on ice for $20 \mathrm{~min}$, the cells were disrupted with 15-20 strokes in a Dounce homogenizer and centrifuged for 5 $\min$ at $300 \times \mathrm{g}$. The pellet was washed once with buffer 1 and suspended in the same buffer. The suspension was brought to $0.3 \mathrm{M} \mathrm{KCl}$ by adding 0.1 volume of buffer 1 containing $3.3 \mathrm{M}$ 
$\mathrm{KCl}$. After gently stirring for $30 \mathrm{~min}$ at $0^{\circ} \mathrm{C}$, the suspension was centrifuged for $1 \mathrm{~h}$ at $200,000 \times \mathrm{g}$ at $4^{\circ} \mathrm{C}$. The supernatant was pooled as nuclear extracts.

Purification of DNA helicase $Q 1$. The nuclear extract was loaded onto a Econo-Pac Q column (BIO-RAD; $5 \mathrm{ml}$ ) equilibrated with $0.3 \mathrm{M} \mathrm{KCl}$ in buffer 2 . The flow-through fraction was pooled and dialyzed against buffer 2 containing $50 \mathrm{mM}$ $\mathrm{KCl}$. The dialysate was loaded onto a FPLC Mono Q column equilibrated with $50 \mathrm{mM} \mathrm{KCl}$ in buffer 2 . The column was washed with $7.5 \mathrm{ml}$ of the equilibration buffer (flow rate, 0.5 $\mathrm{ml} / \mathrm{min}$ ). Proteins were eluted from the column with $20 \mathrm{ml}$ of a linear gradient of $\mathrm{KCl}$ from 50 to $150 \mathrm{mM}$ in buffer 2 . Active fractions that eluted at about $100 \mathrm{mM} \mathrm{KCl}$ were pooled and loaded onto a CM cosmogel equilibrated with $100 \mathrm{mM} \mathrm{KCl}$ in buffer 2 . The column was washed with $7.5 \mathrm{ml}$ of the equilibration buffer (flow rate, $0.5 \mathrm{ml} / \mathrm{min}$ ). Proteins bound to the column were eluted with $30 \mathrm{ml}$ of a linear gradient of $\mathrm{KCl}$ from 100 to $400 \mathrm{mM}$ in buffer 2. DNA-dependent ATPase activity of DNA helicase Q1 was eluted from the column at about 200 $\mathrm{mM} \mathrm{KCl}$. The active fractions were pooled and loaded onto a single-stranded DNA-cellulose column $(1 \mathrm{ml})$ equilibrated with $0.2 \mathrm{M} \mathrm{KCl}$ in buffer 2 . The column was washed with 7.5 $\mathrm{ml}$ of the equilibration buffer (flow rate, $0.5 \mathrm{ml} / \mathrm{min}$ ) and eluted with $30 \mathrm{ml}$ of a linear gradient of $\mathrm{KCl}$ from 0.2 to $1 \mathrm{M}$ in buffer 2. DNA helicase Q1 was eluted from the column at around $0.7 \mathrm{M} \mathrm{KCl}$. The active fractions were pooled and dialyzed against buffer 3 and stored at $-80^{\circ} \mathrm{C}$.

SDS-Polyacrylamide Gel Electrophoresis. SDS-PAGE proceeded essentially as described by Laemmli (8). After electrophoresis, the gels were stained with silver as described by Oakley et al. (17).

Preparation and Purification of Antibody. Synthesized peptides corresponding to the amino acid sequence near the C-terminal of DNA helicase Q1 (EQGDKKMEEKNSGNFQK KAA) were covalently conjugated to keyhole lympet hemocyanin with maleimidobenzoyl-N-hydroxysuccimide $(3,9)$ and used to immunize rabbits as described (29). The sera were checked for their reactivity with dots of antigen peptides on nitrocellulose membranes. Positive sera were collected and purified by antigen peptide-affinity chromatography.

Immunoblotting. Nuclear extracts were developed by SDS-PAGE and transferred to a nitrocellulose membrane at constant current $\left(2 \mathrm{~mA} / \mathrm{cm}^{2}\right)$ for $60 \mathrm{~min}$ with cathode buffer, $25 \mathrm{mM}$ Tris- $\mathrm{HCl}, \mathrm{pH} 9.4,40 \mathrm{mM}$ 6-amino-N-caproic acid, $20 \%$ methanol, and anode buffer, $30 \mathrm{mM}$ Tris- $\mathrm{HCl}$, pH 10.4, $20 \%$ methanol. After transfer, the membrane was soaked in $1 \%$ skim milk in $20 \mathrm{mM}$ Tris- $\mathrm{HCl}, \mathrm{pH} 8.0$ containing $100 \mathrm{mM}$ $\mathrm{NaCl}$ (TBS) for $1 \mathrm{~h}$ to block non-specific protein binding, and then serially immersed in $0.5 \%$ skim milk in TBS containing purified rabbit antibody for $1 \mathrm{~h}$ and in $0.5 \%$ skim milk in TBS containing $37 \mathrm{kBq}$ of $\left[{ }^{125} \mathrm{I}\right]$-protein $\mathrm{A}$ for $1 \mathrm{~h}$. The radioactivity was visualized using Molecular Imager (Bio-Rad).

Immunoprecipitation. Cells were washed twice with icecold PBS and suspended in RIPA buffer $(5 \mathrm{mM}$ Tris- $\mathrm{HCl}, \mathrm{pH}$ $7.5,150 \mathrm{mM} \mathrm{NaCl}, 1 \%$ Triton $\mathrm{X}-100,0.1 \%$ deoxycholate, 1
mM phenylmethylsulfonyl fluoride, $50 \mathrm{mM} \mathrm{NaHSO}$ ). After standing on ice for $20 \mathrm{~min}$, cell lysates were centrifuged for 20 min at $10,000 \times \mathrm{g}$ and the supernatant was recovered as RIPA extracts. Purified antibody was added to RIPA extracts and the sample volumes were adjusted to $200 \mu \mathrm{l}$ with RIPA buffer. After standing on ice for $1 \mathrm{~h}, 70 \mu \mathrm{l}$ of $150 \mathrm{mg} / \mathrm{ml}$ protein A-Sepharose (Pharmacia) in RIPA buffer was added to the samples and shaken for $1 \mathrm{~h}$ at $4^{\circ} \mathrm{C}$. The Protein A-Sepharose was washed five times with RIPA buffer, and then the proteins absorbed to protein A-Sepharose were resolved by SDS-PAGE.

Immunostainning. The cells cultured on Lab-Tek chamber slides were washed twice with ice-cold PBS and fixed with $3.7 \%$ formaldehyde in PBS. The cells were then permeabilized with ice-cold methanol. Thereafter, the slides were soaked in 1\% skim milk in PBS for 30 min to block non-specific protein binding, and then serially immersed in $1 \%$ skim milk in PBS containing purified rabbit antibody for $1 \mathrm{~h}$ and in $1 \%$ skim milk in PBS containing fluorescein isothiocyanate (FITC)-conjugated anti-rabbit IgG (ZYMED Laboratories) for $1 \mathrm{~h}$. The slides were washed with PBS and the cells were observed by fluorescence microscopy.

\section{RESULTS}

Purification of DNA helicase $Q 1$ from $X P-C$ and HeL a cells. We rapidly and efficiently purified DNA helicase Q1 from nuclear extracts as a starting material, as we found that when prepared as described under "MATERIALS AND METHODS" they were enriched with the enzyme. Helicase Q1 was purified from XP-C or HeLa cells by sequential chromatography through Econo-Pac Q, FPLC Mono Q, CM cosmogel, and single-stranded DNA-cellulose columns. The elution profile of DNA helicase Q1 of XP-C cells from the Mono Q column differed from that of HeLa cells as reported (compare Fig. 1A with 1D). However, there was little difference between the DNA helicase Q1 from XP-C and that from HeLa cells in terms of elution profiles from CM cosmogel and single-stranded DNA cellulose columns. Both purified fractions contained one major band on SDS-PAGE of about $73 \mathrm{kDa}$ (Fig. 2).

Comparison of purified DNA helicase Q1. DNA-dependent ATPase and DNA helicase activities of both helicases were examined. Figure 3 shows the nucleic acid requirement for the ATPase activity of helicase Q1. Both enzymes preferred heat-denatured and activated DNA to native DNA and little difference was evident in the requirement for nucleic acids between either enzyme. The DNA helicase activity of both enzymes preferred ATP and dATP as the cofactor and there was virtually no DNA helicase activity with other nucleoside triphosphates. Both enzymes exhibited the same level of DNA helicase activity when used at the same level of DNA-dependent ATPase activity (Fig. 4).

We next examined salt sensitivity of the DNA-depend- 


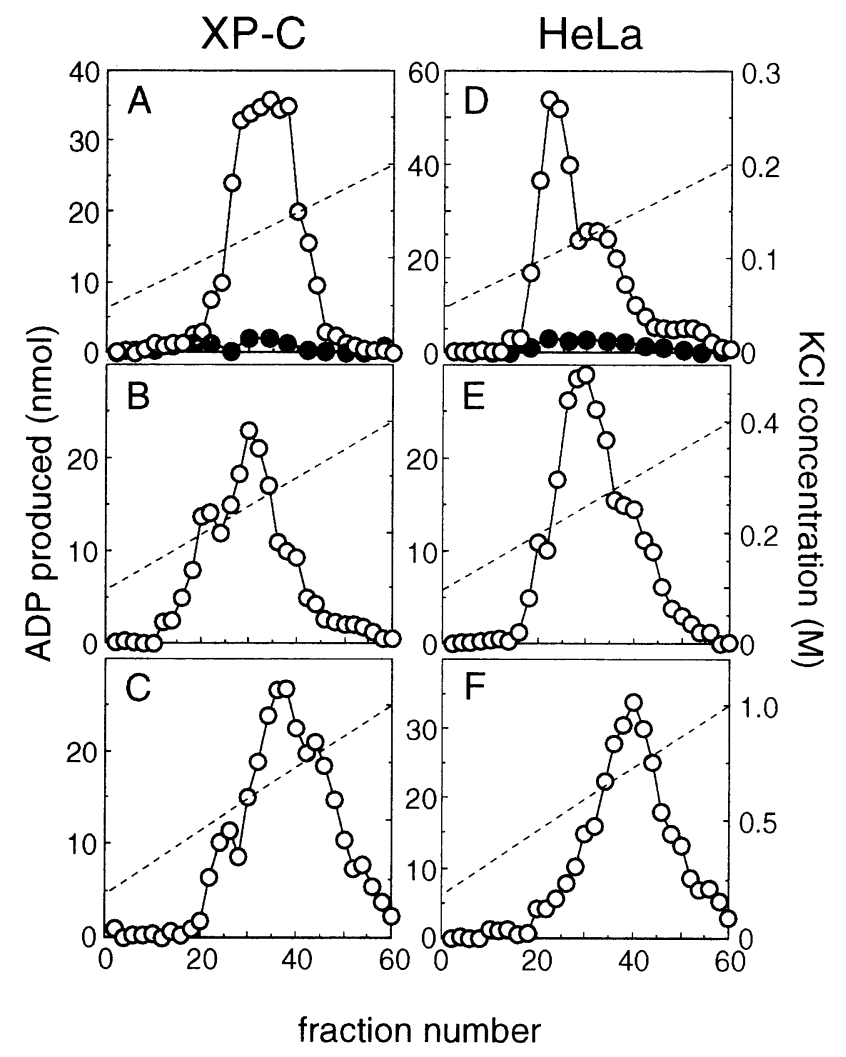

Fig. 1. Purification of DNA helicase Q1 from XP-C and HeLa cells. DNA helicase Q1 was purified from nuclear extracts by sequential column chromatography through Econo-Pac Q, FPLC Mono Q, CM cosmogel, and ssDNA-cellulose columns as described under "MATERIALS AND METHODS". Aliquots of each fraction were assayed for ATPase activity in the presence of $5 \mu \mathrm{g}$ heat-denatured DNA $(\bigcirc$ ) or absence (O). A, FPLC Mono Q column elution profile of XP-C extracts; B, CM cosmogel of XP-C; C, ssDNA-cellulose of XP-C; D, FPLC Mono Q of HeLa cells; E, CM cosmogel of HeLa; F, ssDNA-cellulose of HeLa.

ent ATPase activity of both enzymes because DNA helicase Q1 from XP-C cells was eluted from the Mono Q column at higher concentrations of $\mathrm{KCl}$ than that from HeLa cells (Fig. 1). The DNA-dependent ATPase activity of both enzymes showed similar salt sensitivity (Fig. 5).

Figure 6 shows the time courses of DNA-dependent ATPase activity of both helicases at 32,37 , and $42^{\circ} \mathrm{C}$. The rate of ATP hydrolysis by DNA helicase Q1 from $\mathrm{XP}-\mathrm{C}$ cells at $42^{\circ} \mathrm{C}$ was about 1.5 -fold higher than that at $37^{\circ} \mathrm{C}$ and the rate at $32^{\circ} \mathrm{C}$ was about one-half of the rate at $37^{\circ} \mathrm{C}$. Again, there was no difference between the two DNA helicase Q1 in the rate of ATP hydrolysis at each temperature.

Characterization of DNA helicase Q1 with an anti$D N A$ helicase $Q 1$ antibody. We prepared an antiDNA helicase Q1 antibody using the peptide corresponding to the amino acid sequence near the $\mathrm{C}$-termi-

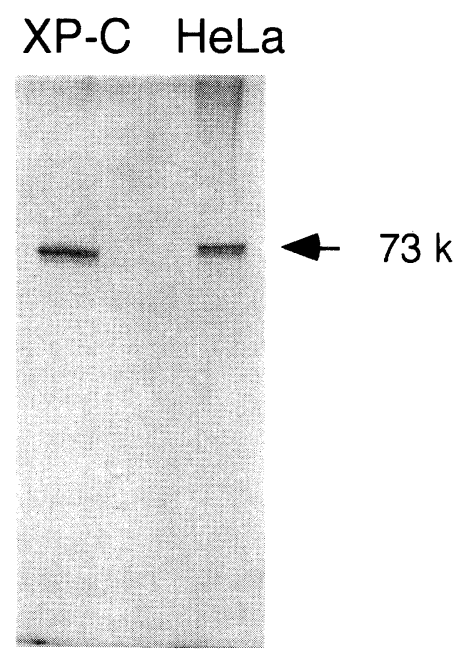

Fig. 2. SDS-PAGE of purified fractions of DNA helicase Q1. Purified fractions of XP-C and HeLa cells were resolved by 10\% SDS$P A G E$ and stained with silver.

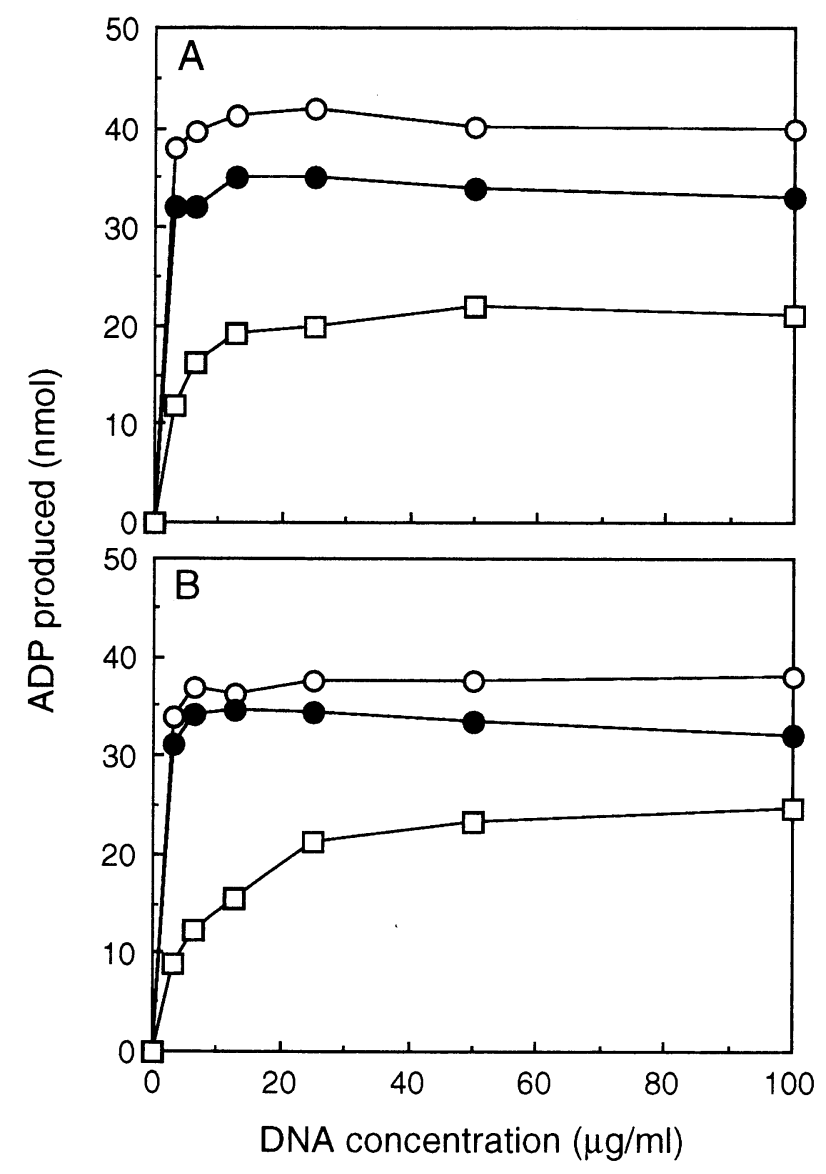

Fig. 3. ATPase activity of DNA helicase $Q 1$ as a function of the concentration of various DNAs. DNA helicase Q1s from XP-C (A) and HeLa (B) cells (40 units of DNA-dependent ATPase activity) were incubated for 60 min under the standard conditions in the presence of various concentrations of heat-denatured DNA $(\bigcirc)$, activated DNA (O) and native DNA $(\square)$. 


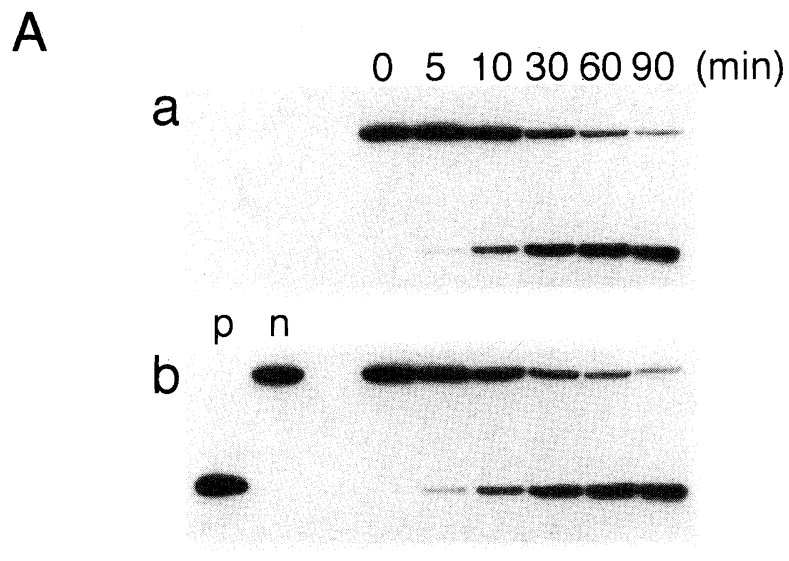

B

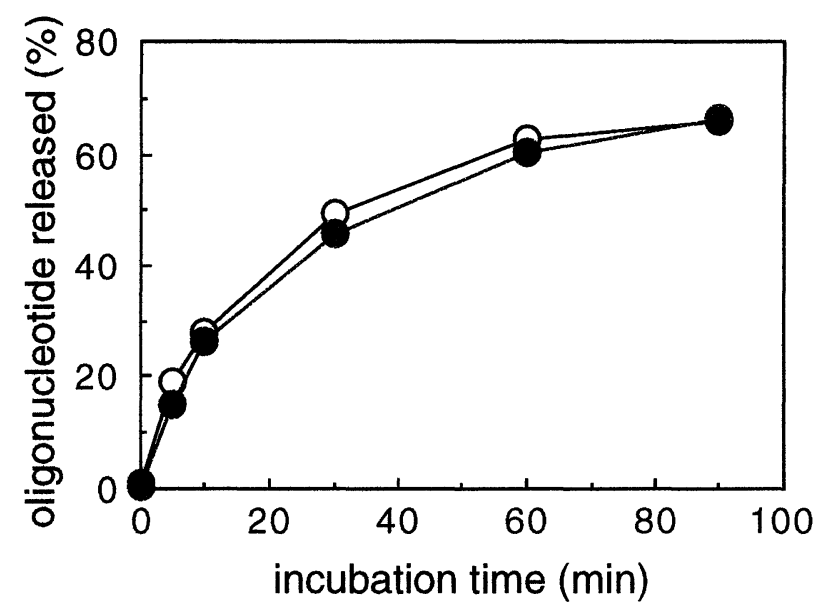

Fig. 4. Time course of DNA helicase activity. A, DNA helicase Q1 from XP-C (a) and HeLa (b) cells (40 units of DNA-dependent ATPase activity) were assayed for DNA helicase activity under the standard conditions for 5, 10, 30, 60, and $90 \mathrm{~min} . \mathrm{n}$ (negative control) incubated at $37^{\circ} \mathrm{C}$ without enzyme; $p$ (positive control) heated in boiling water for 2 min without enzyme. B, DNA helicase activity was measured as described under "MATERIALS AND METHODS". $\bigcirc$, DNA helicase Q1 from XP-C cells; DNA helicase Q1 from HeLa cells.

nus of DNA helicase Q1. This antibody was affinitypurified using an antigen peptide-conjugated column. We immunoblotted nuclear extracts resolved by SDSPAGE against this antibody, which recognized a polypeptide with a molecular mass of about $73 \mathrm{kDa}$ (Fig. 7) that coincided with that of purified DNA helicase Q1 (Fig. 1). This indicated that the DNA helicase Q1 was not degraded during the purification. In addition, a single band was observed when the mixture of extracts from these cells was resolved by SDS-PAGE. These results indicated that the molecular masses of the helicase

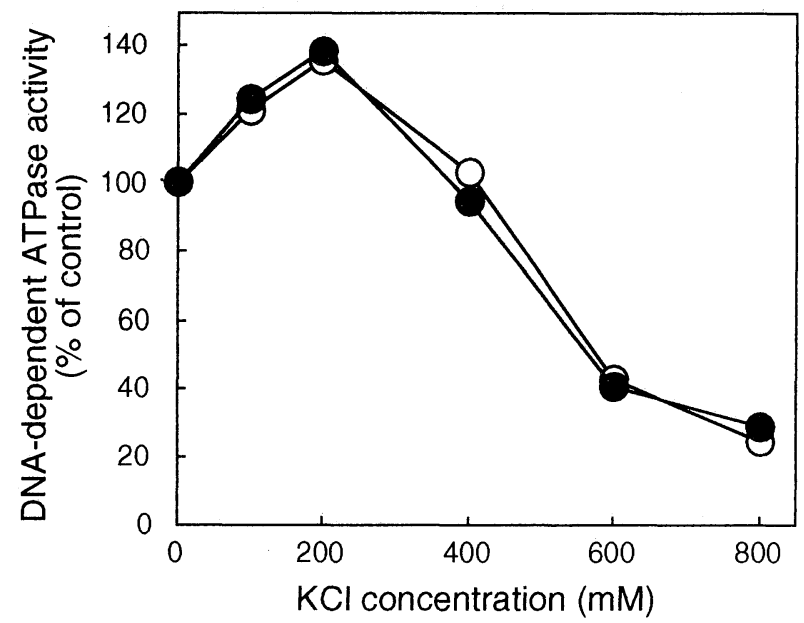

Fig. 5. Effect of $\mathrm{KCl}$ on DNA-dependent ATPase activity of DNA helicase Q1. DNA-dependent ATPase activity of DNA helicase Q1s (40 units) from XP-C (O) and HeLa (O) cells was assayed under the standard conditions in the presence of the indicated concentrations of $\mathrm{KCl}$.

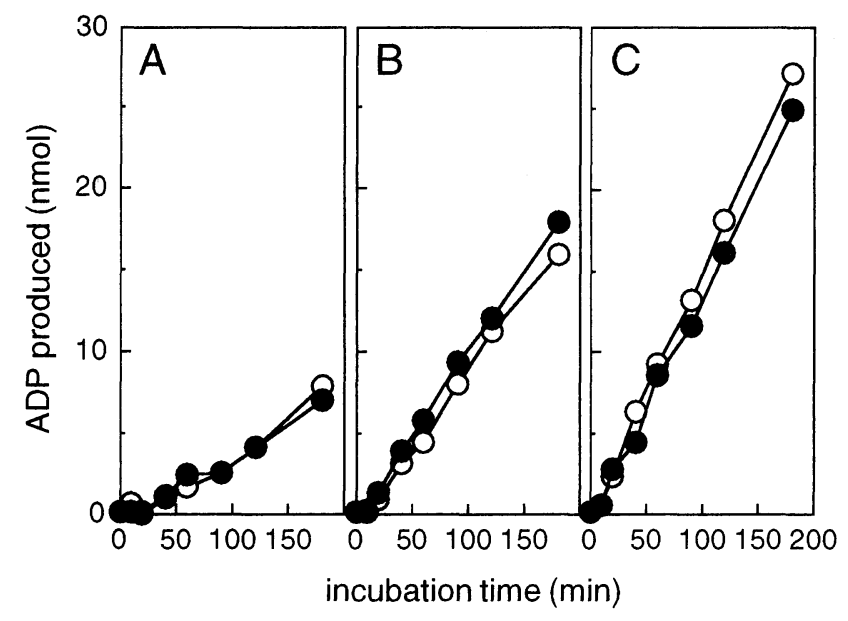

Fig. 6. DNA-dependent ATPase activity of DNA helicase Q1 at various temperatures. DNA-dependent ATPase activity of DNA helicase Q1s (6 units) from XP-C $(\bigcirc)$ and $\mathrm{HeLa}(O)$ cells was assayed at 32 (A), 37 (B), and $42(\mathrm{C}){ }^{\circ} \mathrm{C}$ for the indicated periods.

from XP-C and HeLa cells were the same.

To investigate the interaction of the helicase with other proteins, DNA helicase Q1 was immunoprecipitated using the purified antibody. Figure 8 shows the SDS-PAGE profile of precipitated proteins. A $73 \mathrm{kDa}$ protein precipitated from both XP-C and HeLa cell extracts (lanes 1 and 5) disappeared when exposed to the antibody that had been incubated with the antigen peptide (lanes 2 and 4). If some proteins co-precipitate with DNA helicase Q1 by interacting with the helicase, the bands corresponding to the interacting proteins would disappear in the case of the preincubated antibody. 


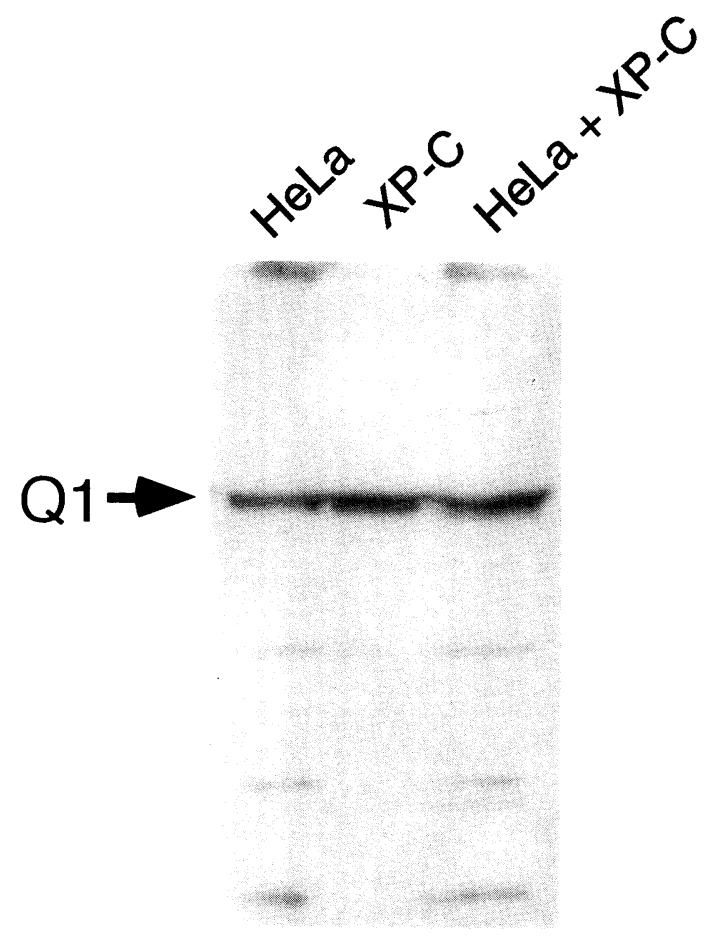

Fig. 7. Immunoblotting with anti-DNA helicase $\mathrm{Q} 1$ antibody. The nuclear extract from $5 \times 10^{6} \mathrm{XP}-\mathrm{C}$ cells, that from $2.5 \times 10^{7} \mathrm{HeLa}$ cells, or the mixture of these nuclear extracts was resolved by SDSPAGE and blotted to a nitrocellulose membrane. The blot was probed with the affinity-purified anti-DNA helicase Q1 antibody.

However, none of the bands disappeared with the 73 $\mathrm{kDa}$ band (compare lane 1 with 2 and 4 with 5). These results indicated that the interaction of proteins with DNA helicase Q1, if any, is so weak that it is destroyed during the preparation of cell extracts and immunoprecipitation.

We examined the modification of DNA helicase Q1 in intact cells. XP-C and WI38VA13 cells were labeled with [32P]orthophosphate and nuclear extracts were prepared. DNA helicase Q1 was immunoprecipitated from the nuclear extracts with the anti-DNA helicase Q1 antibody. The immunoprecipitated DNA helicase Q1 migrated as a $73 \mathrm{kDa}$ band in SDS-PAGE as shown in Figure 2 (data not shown). However, radioactivity was barely detectable in the position where DNA helicase Q1 migrated (Fig. 9). Similar results were obtained using extracts from HeLa cells. These results indicated that DNA helicase Q1 is not modified by incorporating phosphate groups by processes such as phosphorylation and ADP-ribosylation.

Intracellular localization of DNA helicase Q1. The intracellular localization of DNA helicase Q1 in intact cells was determined by immunofluorescence. Cells were fixed and incubated with anti-DNA helicase Q1 antibody and followed by FITC-conjugated anti-rabbit an-

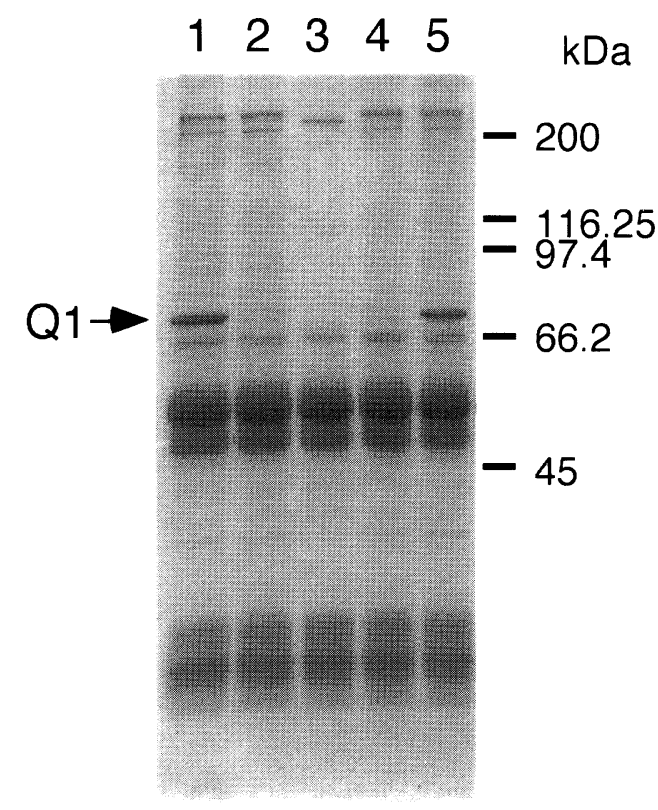

Fig. 8. Immunoprecipitation of DNA helicase Q1. The extracts prepared from $5 \times 10^{6} \mathrm{XP}-\mathrm{C}$ cells (lanes 1 and 2 ) and $2.5 \times 10^{7} \mathrm{HeLa}$ cells (lanes 4 and 5) were exposed to the affinity-purified anti-DNA helicase Q1 antibody (lanes 1, 3 and, 5) and that preincubated with the antigen peptide (lanes 2 and 4). The sample in lane 3 contained RIPA buffer instead of extracts. The band corresponding to DNA helicase Q1 is indicated by an arrow.

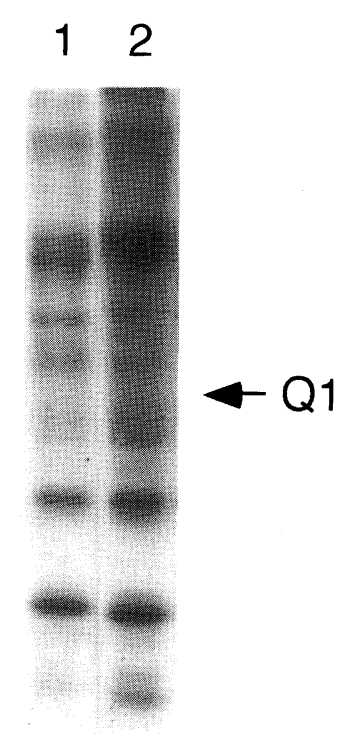

Fig. 9. Check of incorporation of phosphate group into DNA helicase Q1. XP-C cells (lane 1) and human fibroblasts, WI38VA13 cells (normal in repair) (lane 2) were labeled with $100 \mathrm{kBq}$ of $\left[{ }^{32} \mathrm{P}\right]$-orthophosphate for $24 \mathrm{~h}$. Nuclear extracts were prepared from labeled cells and the extracts were immunoprecipitated with anti-DNA helicase Q1 antibody as described in "MATERIALS AND METHODS". After SDS-PAGE, radioactivity incorporated into proteins was visualized with a Molecular Imager (Bio-Rad). 


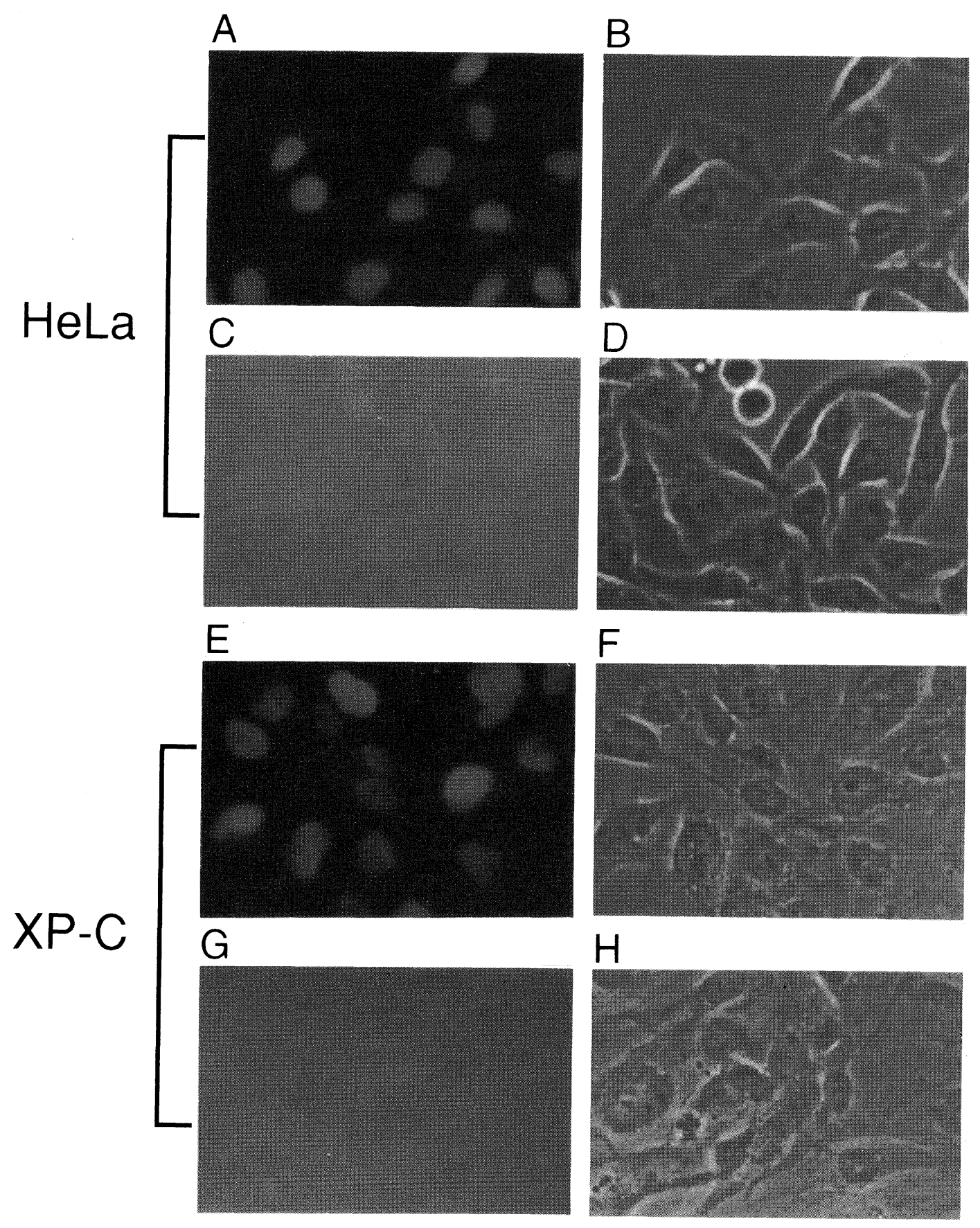

Fig. 10. Immunostaining of DNA helicase $\mathrm{Q} 1$ in $\mathrm{HeLa}$ and XP-C cells. HeLa (A-D) and XP-C cells (E-H) were incubated with anti-DNA helicase Q1 antibody and stained as described under "MATERIALS AND METHODS". Panels A, C, E and G show images of fluorescence microscopy, and panels B, D, F and $\mathrm{H}$ show the images of phase-contrast microscopy corresponding to panels A, C, E and G, respectively. The antibody preincubated with the antigen peptide was used in the experiments shown in panels $\mathrm{C}, \mathrm{D}, \mathrm{G}$ and $\mathrm{H}$.

tibody. Figure 10E shows the immunofluorescence of XP-C cells. The nuclei were stained brightly, while the cytoplasm was not. There was no staining in the nuclei of cells exposed to the anti-Q1 antibody which was incubated with the antigen peptide (Fig. 10G). Similar re- sults were obtained with HeLa cells (Fig. 10A and C).

\section{DISCUSSION}

E. coli RecQ is a member of the RecF family, which 
is involved in plasmid recombination and repair of UVdamaged DNA $(15,16)$. However, the precise role of this protein has not yet been clarified. The cDNAs encoding for human and S. cerevisiae homologue of RecQ have been cloned $(6,18,24)$. Analyses of strains lacking the yeast homologue, Sgs1, indicate that Sgs1 is involved in the faithful segregation of nascently replicated chromosomes (31). We also analyzed the properties of sgsl disruptants and found that they were more sensitive to methyl methanesulfonate than wild-type cells, and the frequency of recombination occurring in meiotic phase was considerably decreased in the disruptants, indicating that eukaryotic RecQ is involved in some type of DNA repair and DNA recombination (unpublished results).

In this study, we characterized the properties of DNA helicase Q1, human RecQ, using an anti-DNA helicase Q1 antibody and clarified several issues.

DNA helicase Q1 localized in the nuclei. The results of immunostaining coincided with those of biochemical fractionation, where DNA helicase Q1 was mainly recovered from the nuclear fraction. Thus, in this study, DNA helicase Q1 was purified from nuclear extracts. Although the staining profile did not allow the unambiguous assignment of DNA helicase Q1 to specific locations, nucleolar-like structures were stained only weakly. In XP-C cells, the intensity of the fluorescence seemed to vary from cell to cell. This may be due to the difference of the growth-state of the cells because preliminary experiments using Swiss 3T3 cells indicated that the expression of DNA helicase Q1 increased during the transition from resting phase to growing phase.

DNA helicase Q1 is not modified by incorporating phosphate groups through processes such as phosphorylation and ADP-ribosylation.

The interaction of DNA helicase Q1 with other proteins was not indicated under our conditions. However, Gangroff et al. (6) have indicated the interaction of $S$. cerevisiae RecQ (Sgs1) with DNA topoisomerase III and Watt et al. (31) indicated the interaction of Sgs1 with topo II using the two-hybrid system. The inability to detect the interaction of human RecQ with these topoisomerases can be explained as follows. The interaction of DNA helicase Q1 with these topoisomerases is too weak to be maintained during the process of immunoprecipitation or only a small portion of these topoisomerases interact with DNA helicase Q1, resulting in their being below the level of detection under our experimental conditions. Another explanation is that DNA helicase Q1 has no site to interact with these topoisomerases because Sgs1 interacts with DNA topoisomerases II and III at its N-terminal region, most of which is not conserved in human and $E$. coli $\operatorname{RecQ}(6,31)$.

We tried to clarify why the elution profile of DNA helicase Q1 of XP-C cells from Mono Q column is altered as shown in Fig. 1. The alteration may be due to a mutation of the DNA helicase Q1 gene in XP-C cells or to a secondary effect of the mutation of XP-C cells, such as an altered modification of DNA helicase Q1 or interaction of the helicase with other proteins.

We purified DNA helicase Q1 from XP-C and HeLa cells and compared their properties. DNA helicase Q1 from both cell lines had a molecular mass of $73 \mathrm{kDa}$ and the same enzymatic properties even, including salt sensitivity. In addition, it has been indicated that a gene encoding a protein other than DNA helicase Q1 is altered in XP-C cells $(10,12)$. Thus it seems unlikely that the gene encoding for DNA helicase Q1 is altered in XP-C cells.

The alteration in the modification of DNA helicase Q1, which attaches phosphate groups such as phosphorylation and ADP-ribosylation, was denied by the results shown in Fig. 9. However, alterations of other types of modification remain to be examined.

The alteration in the interaction of DNA helicase Q1 from XP-C cells with other proteins was not indicated in the purified (Fig. 2) and immunoprecipitated fractions (Fig. 8). However, these results do not completely exclude the possibility of an alteration in the interaction of the helicase with other proteins, because it is conceivable that the interaction is too weak to be maintained during purification or immunoprecipitation. In this context, it is important to confirm whether or not the purified DNA helicase Q1 from XP-C cells still elutes from FPLC Mono Q column at higher concentrations of $\mathrm{KCl}$ than that from HeLa cells. We examined the elution profile of the purified DNA helicase Q1 from XP-C and HeLa cells. However, we could not obtain reproducible results.

To identify weakly interacting proteins, we used a two-hybrid strategy and cloned a cDNA encoding Rch1 (Rag cohort), which had been cloned as a cDNA encoding a protein interacting with Rag1 (2) required for $\mathrm{V}$ (D) $\mathrm{J}$ recombination (data not shown). A preliminary experiment indicated that an Rch1-glutathione S-transferase fusion protein interacted with DNA helicase Q1 in $\mathrm{HeLa}$ cell extracts but not with that in XP-C cell extracts. More precise analyses of the interaction of Rch1 with both DNA helicase Q1s are now in progress.

\footnotetext{
Acknowledgments. We thank to Dr. M. Tomita, Faculty of Pharmaceutical Sciences, Showa University, for synthesizing the peptide under support of a grant for Cancer Research from the Ministry of Education, Science and Culture of Japan. This work was supported by Grants-in Aid for Scientific Research and for Scientific Research on Priority Areas (05270101) from the Ministry of Education, Science and Culture of Japan.
} 


\section{REFERENCES}

1. Alberts, B. and Herrick, G. 1971. DNA-cellulose chromatography. Methods in Enzymol., 21: 198-217.

2. CuOmo, C.A., Kirch, S.A., Gyuris, J., Brent, R., and OETTINGER, A. 1994 . Rch1, a protein that specifically interacts with the RAG-1 recombination-activating protein. Proc. Natl. Acad. Sci. USA, 91: 6156-6160.

3. Davies, A., Meeran, K., Cairns, M.T., and Baldwin, S.A. 1987. Peptide-specific antibodies as probes of the orientation of the glucose transporter in the human erythrocyte membrane. J. Biol. Chem., 262: 9347-9352.

4. Drapkin, R., Reardon, J.T., Ansarl,, A., Huang, J.-C., Zawel, L., Ahn, K., Sancar, A., and Reinberg, D. 1994. Dual role of TFIIH in DNA excision repair and in transcription by RNA polymerase II. Nature, 368: 769-772.

5. Flejiter, W.L., McDaniel, L.D., Johns, D., Friedberg, E.C., and Schultz, R.A. 1992. Correction of xeroderma pigmentosum complementation group D mutant cell phenotype by chromosome and gene transfer: involvement of the human ERCC2 DNA repair gene. Proc. Natl. Acad. Sci. USA, 89: 261265.

6. Gangloff, S., McDonald, J.P., Bendixen, C., Arthur, L., and RothSTEIN, R. 1994. The yeast type I topoisomerase top3 interacts with Sgs1, a DNA helicase homologue: a potential eukaryotic reverse gyrase. Mol. Cell. Biol., 14: 8391-8398.

7. Korn, L.J. and YANOFSKY, C. 1976. Polarity suppressors defective in transcription termination at the attenuator of the tryptophan operon of Escherichia coli have altered rho factor. $J$. Mol. Biol., 106: 231-241.

8. LAEMMLI, U.K. 1970. Cleavage of structural proteins during the assembly of the head of bacteriophage T4. Nature, 227: 680-685.

9. LaRochelle, W.J., Wray, B.E., Sealock, R., and Froehner, S.C. 1985. Immunochemical demonstration that amino acids 360-377 of the acetylcholine receptor gamma-subunit are cytoplasmic. J. Cell Biol., 100: 684-691.

10. Legerski, R. and Peterson, C. 1992. Expression cloning of a human DNA repair gene involved in xeroderma pigmentosum group C. Nature, 359: 70-73.

11. Lohman, T.M. 1993. Helicase-catalyzed DNA unwinding. $J$. Biol. Chem., 268: 2269-2272.

12. Masutani, C., Sugasawa, K., Yanagisawa, J., Sonoyama, T., Ui, M., Enomoto, T., Takio, K., TanaKa, K., VAN DER SPeK, P.J., Bootsma, D., Hoeismakers, J.H.J., and HaNaOKa, F. 1994. Purification and cloning of a nucleotide excision repair complex involving the xeroderma pigmentosum group $\mathrm{C}$ protein and a human homologue of yeast RAD23. EMBO J., 13: $1831-1843$.

13. Matson, S.W. and Kaiser-Rogers, K.A. 1990. DNA helicases. Annu. Rev. Biochem., 59: 289-329.

14. Matson, S.W., Bean, D.W., and George, J.W. 1994. DNA helicases: enzymes with essential roles in all aspects of DNA metabolism. BioEssays, 16: 13-22.

15. Nakayama, H., Nakayama, K., Nakayama, R., Irino, N., Nakayama, Y., and Hanawalt, P.C. 1984 . Isolation and genetic characterization of a thymineless death-resistant mutant of Escherichia coli K12: identification of a new mutant (recQI) that blocks the RecF recombination pathway. Mol. Gen. Genet., 195: 474-480.

16. Nakayama, K., Irino, N., and Nakayama, H. 1985 . The RecQ gene of Escherichia coli K12: molecular cloning and insertion mutants. Mol. Gen. Genet., 200: 266-271.
17. OAKLEY, B.R., KIRSCH, D.R., and MorRIS, N.R. 1980. A simplified ultrasensitive silver stain for detecting proteins in polyacrylamide gels. Anal. Biochem., 105: 361-363.

18. Puranum, K.L. and Blackshear, P.J. 1994. Cloning and characterization of RECQL, a potential human homologue of the Escherichia coli DNA helicase RecQ. J. Biol. Chem., 269: 29838-29845.

19. Schaeffer, L., Monocollin, V., Roy, R., Staub, A., Mezzina, M., Sarasin, A., Weeda, G., HoeiJMakers, J.H.J., and EGLY, J.-M. 1993. The ERCC2/DNA repair protein is associated with the class II BTF2/TFIIH transcription factor. EMBO J., 13: 2388-2392.

20. Schaeffer, L., Roy, R., Humbert, S., Monocollin, V., Vermeulen, W. Hoeijmakers, J.H.J., Chambon, P., and EGLY, J.-M. 1993. DNA repair helicase: a component of BTF2 (TFIIH) basic transcription factor. Science, 260: 58-63.

21. SeKi, M., Enomoto, T., Hanaoka, F., and Yamada, M. 1987. DNA-dependent adenosinetriphosphatase B from mouse FM3A cells has DNA helicase activity. Biochemistry, 26: 2924-2928.

22. Seki, M., Enomoto, T., Yanagisawa, J., Hanaoka, F., and UI, M. 1988. Further characterization of DNA helicase activity of the mouse DNA-dependent adenosinetriphosphatase B, DNA helicase B. Biochemistry, 27: 1766-1771.

23. Seki, M., Yanagisawa, J., Kohda, T., Sonoyama, T., Ui, M., and Еломото, T. 1994. Purification of two DNA-dependent adenosinetriphosphatases having DNA helicase activity from HeLa cells and comparison of the properties of the two enzymes. J. Biochem., 115: 523-531.

24. Seki, M., MiYazawa, H., Tada, S., Yanagisawa, J., Yamaoka, T., Hoshino, S., Ozawa, K., Eki, T., Nogami, M., OKumura, K., Taguchi, H., Hanaoka, F., and Enomoto, T. 1994. Molecular cloning of cDNA encoding human DNA helicase Q1 which has homology to Escherichia coli RecQ helicase and localization of the gene at chromosome 12p12. Nucleic Acids Res., 22: 4566-4573.

25. Sung, P., Bailly, V., Weber, C., Thompson, L.H., Prakash, L., and PraKash, S. 1993. Human xeroderma pigmentosum group D gene encodes a DNA helicase. Nature, 365: 852-855.

26. Tanuma, S., Enomoto, T., and Yamada, M. 1980. Characterization of DNA synthesis in salt-treated HeLa cell nuclei. Cell Struct. Funct., 5: 27-37.

27. ТнӧмmеS, R. and HüвSCHER, U. 1992. Eukaryotic DNA helicases: essential enzymes for DNA transactions. Chromosoma, 101: 467-473.

28. Umezu, K., Nakayama, K., and Nakayama, H. 1992. Escherichia coli Rec Q protein is a DNA helicase. Proc. Natl. Acad. Sci. USA, 87: 5363-5367.

29. VAituKaITIS, J.L. 1981. Production of antisera with small doses of immunogen: multiple intradermal injections. Methods Enzymol., 73: 46-52.

30. Vermeulen, W., Stefanini, M., Giliani, S., Hoeijmakers, J.H.J., and BootsMA, D. 1991. Xeroderma pigmentosum complementation group $\mathrm{H}$ falls into complementation group D. $\mathrm{Mu}$ tation Res., 255: 201-208.

31. Watt, P.M., Louis, E.J., Borts, R.H., and Hickson, I.D. 1995. Sgs1: a eukaryotic homolog of $E$. coli RecQ that interacts with topoisomerase II in vitro and is required for faithful chromosome segregation. Cell, 81: 253-260.

32. Weber, C.A., Salazar, E.P., Stewart, S.A., and Thompson, L.H. 1990. ERCC2: cDNA cloning and molecular characterization of a human nucleotide excision repair gene with high homology to yeast RAD3. EMBO J., 9: 1437-1447.

33. Weeda, G., van Ham, R.C.A., Masurel, R., Westerveld, A., 
OdiJK, H., DE Wit, J., Bootsma, D., VAN DER Eb, A.J., and HoEIJMAKERS, J.H.J. 1990. Molecular cloning and biological characterization of the human excision repair gene ERCC3. Mol. Cell. Biol., 10: 2570-2581.

34. Weeda, G., van Ham, R.C.A., Vermeulin, W., Bootsma, D., VAN DER Eb, A.J., and HoeIJMAKers, J.H.J. 1990. A presumed DNA helicase encoded by ERCC3 is involved in the human repair disorders xeroderma pigmentosum and Cockayne's syndrome. Cell, 62: 777-791.
35. Yanagisawa, J., SeKi, M., Ui, M., and Enомото, T. 1992. Alteration of a DNA-dependent ATPase activity in xeroderma pigmentosum complementation group C cells. J. Biol. Chem., 267: $3585-3588$.

(Received for publication, November 29, 1995

and in revised form, February 28, 1996) 